\title{
Mod3D: A Low-Cost, Flexible Modular System of Live-Cell Microscopy Chambers and Holders
}

Barba Bazan, C ${ }^{1}$. Goss, S. ${ }^{1}$, Peng, C. ${ }^{1}$, Begeja, N. ${ }^{1}$, Suart CE. ${ }^{1}$, , Neuman, K. ${ }^{1}$, and Ray Truant ${ }^{1,2}$

${ }^{1}$ Department of Biochemistry and Biomedical Sciences, McMaster University. Hamilton, Ontario, Canada, L8N3Z5. ${ }^{2}$ Center for Advanced Light Microscopy (CALM), McMaster University.

*To Whom Correspondence Should Be Addressed, truantr@mcmaster.ca

\begin{abstract}
Live-cell microscopy imaging typically involves the use of high-quality glass-bottom chambers that allow cell culture, gaseous buffer exchange and optical properties suitable for microscopy applications. However, commercial sources of these chambers can add significant annual costs to cell biology laboratories. Consumer products in three-dimensional printing technology, for both Filament Deposition Modeling (FDM) and Masked Stereo Lithography (MSLA), have resulted in more biomedical research labs adopting the use of these devices for prototyping and manufacturing of lab plastic-based items, but rarely consumables. Here we describe a modular, live-cell chamber with multiple design options that can be mixed per experiment. Single reusable carriers and the use of biodegradable plastics, in a hybrid of FDM and MSLA manufacturing methods, reduce plastic waste. The system is easy to adapt to bespoke designs, with concept-to-prototype in a single day, offers significant cost savings to the users over commercial sources, and no loss in dimensional quality or reliability.
\end{abstract}

\section{Introduction}

Live-cell microscopy imaging has evolved from single chamber observations to large-scale uses in High Content Analysis. Commercial live-cell imaging chambers and plates are produced to stringent manufacturing standards and typically involve injection molded thermoplastic bonded to the glass. However, these chambers are typically expensive relative to 6-, 12-, and 96-well plate formats and plastic dishes, often by an order of magnitude or more, due to the required strict quality control. Strict manufacturing standards ensure the dishes are flat and are reliably constructed to hold media without leaking. Assembled live-cell chambers are available from commercial sources, but are machined in metal or plastic and are typically very expensive and limited in the scope of use, but are a common choice for perfusion experiments. However, in a typical cell biology laboratory, these live cell chambers can add significant costs.

3D printing methods to manufacture plastic-based items have been historically reliant on expensive commercial industrial printers protected by a series of hardware and software patents. From 2015, open-source software-driven kits and complete printers cut the costs of these devices drastically. This initiative was started at the University of Bath as the replicating rapid prototyper (RepRap) project in 2005 [1], which was released publicly as an open, free licence and GNU general public license. This open-source hardware design was coupled to open-sourced Marlin firmware which could translate 3D modelled shapes into G-code machine commands to direct the tool movements in 3D printers. Marlin runs on inexpensive 8-bit Atmel microcontroller chips at the center of the open-source Arduino/Genuino platform [2]. Most early designs were filament deposition modelling, or FDM, in which a plastic filament 
is forced into a heated extruder at the glass-transition melting point of the material to layer patterns in a Cartesian XYZ space. Mixed orientations of the layer depositions give models high strength in multiple directions of force and are typically flat within 50 micrometers.

Another type of 3D printing, stereolithography (SLA), does not use filaments nor heat, but rather UV-crosslinked resin layers in patterns directed by a $<405 \mathrm{~nm}$ laser line controlled by a mirror and galvanometer. This was further derived to Masked Stereo Lithography (MSLA) by the use of inexpensive light-emitting diode (LED) arrays and consumer electronics-sourced liquid crystal displays (LCD) to replace the galvanometer-directed laser light with a lithography mask created by the LCD in front of an array of $405 \mathrm{~nm}$ LEDs. A platform controlled by a stepper motor can then provide resolutions in $\mathrm{Z}$ as little as 25 micrometers, with an XY resolution below 100 micrometers. For both FDM and MSLA consumer printers, costs have been reduced to under US\$300. Thus, subsequent adoption to research labs is becoming increasingly popular for the use of small research-based plastic objects such as racks, holders, brackets, and protein models, but typically not replacing plastic consumables. The cost of scientific laboratory use of injection molded consumable plastics is typically driven by high costs of tool and die manufacturing and the limited markets of potential recovery of those costs. However, these factors are not affected by 3D printing.

Here we sought to manufacture a lab consumable: live-cell microscopy incubation chambers manufactured by MSLA, bonded to standard 22x22mm glass coverslips, held within universal 96-well format platforms manufactured by FDM, self-assembled with magnets, and designed to be reused. We set out to achieve ease of manufacture, low cost, ability to modify for bespoke applications, reliable containment of media; high dimensional quality, a portion of reusability and reduced environmental impact through the use of minimal/ biodegradable plastic. The designs were evolved to be modular, allowing a mix of well sizes and types as opposed to one set format with unused wells. Each design can be used within a single universal 96-well format stage holder, minimizing waste and maximizing experimental flexibility.

\section{Results}

The challenges of this project included many $(>100)$ empirical attempts of designs, first using just FDM printing. We attempted to use both polylactic acid (PLA) as well as Polyethylene Terephthalate Glycol (PETG) filaments for 3D printing. We found this method unreliable, with the resolution not up to the standards required, a poor ability of FDM prints to be watertight, and a glass bonding surface with too many potential imperfections to allow reliable bonding. The printing time was also several hours by printing chamber replicates. However, we did find the use of FDM superior for the chamber holder, which we designed on a universal 96-well size format at $4 \mathrm{~mm}$ thickness with a $20 \%$ grid infill to provide a very strong, flat and stiff platform that did not expand or change dimensions up to $37^{\circ} \mathrm{C}$ (Fig.1a). We settled on a final design that could hold up to three $22 \times 50 \mathrm{~mm}$ chambers, or six $22 \times 22 \mathrm{~mm}$ chambers (Fig. $1 \mathrm{~b}$ ) with the overall dimensions of a universal plastic 96-well dish and a lid made of a frame of FDM plastic bonded to a cut sheet of $0.2 \mathrm{~mm}$ polystyrene (Fig. $1 \mathrm{c}-\mathrm{e}$ ). Within the top and bottom halves of the holder, two or four $5 \times 1 \mathrm{~mm}$ neodymium magnets on each half were used to self-assemble the lid onto the base (Fig.1 c-e) and hold the chambers in place to prevent floating under objective pressure while using water or oil immersion objectives. Directional arrows, a logo, and one chamfered corner were incorporated into the design to aid with orientation. Each half of the chamber holders can take 2-2.5hrs to print at standard settings on the printer (200 micrometer layers), but these holders and lids can be reused with a sterilization cycle indefinitely.

For the chambers, we switched from using FDM to printing with MSLA resin. This solved two problems: the MSLA prints are essentially one piece of plastic, so leaking was never observed, and the 
top final surface of the print was extremely high quality for glass bonding. We took advantage of the high print resolution to emboss an alphanumeric labelling of chambers onto the sides to keep track of well identities during experiments. The base design was a $22 \times 50 \mathrm{~mm}$ chamber that fit two standard 22x22mm \#1.5 glass coverslips, with a bonding surface of $1.5 \mathrm{~mm}$ wide edges, ensuring a reliable bond between the plastic and glass. Within this base template (Fig. 2 a-e), we were then able to design multiwell plates up to 32 wells per chamber, or 96 wells total within a single three-position carrier. Chambers were designed so that a 150 micrometer coverslip (\#1.5) sat 100 micrometers below the plastic holder to prevent any friction between objective lenses and holder plastic during $X Y$ travel.

For bonding the coverslips to the plastic chamber, we previously successfully used room temperature vulcanization (RTV) silicone (Silicone I, General Electric) on manufactured plates in which we milled a hole on the bottom of a 35-mm tissue culture dish [3]. RTV silicone has excellent glass bonding properties, is resistant to all solvents used in cell fixation and permeabilization and can withstand temperatures from $-60^{\circ} \mathrm{C}$ to $200^{\circ} \mathrm{C}$. We found two-component silicones cured too quickly for practical handling and Vinyl-terminated Polydimethylsiloxane (PDMS) (Silguard, Dow Chemical) had poor adhesive properties or required priming steps. RTV silicones can be cured by the release of acetic acid or oxime-based curing. Both curing compounds can be toxic to cells, so either a full cure time of 72 hrs was required, or cure time could be accelerated to $16 \mathrm{hrs}$ when left in the high humidity of a tissue culture incubator. The choice of RTV silicone was a combination of cost considerations, ease of use, availability and reliability of bonding. We found the oxime-based curing RTV (SS-433T, Silicone Solutions, $\mathrm{OH}, \mathrm{USA}$ ) to be optimal because of lower viscosity which helps with evening the spread of glue on $>16$-well chambers. To apply the adhesive evenly and ensure a flat bonded surface, a $30 \mathrm{~mm}$ diameter soft polymer craft roller was used to spread the glue on a $20 \times 20 \mathrm{~cm}$ sheet of phenolic resin or glass to generate a thin coat on the roller face, then to transfer this thin layer of glue to the chamber bonding face. Coverslips were then placed on the adhesive surface and pressed evenly with a 3D printed block (Supplemental Video 1). We prototyped using clear resin, but found light scattering too problematic for fluorescent microscopy use and switched to opaque black resin. 3D printing also cannot produce optically clear plastic without polishing. Therefore, lids for the chambers were made either by FDM printing the frames and bonding a coverslip glass using RTV silicone (Fig. 2h), or by printing with a solid top for inverted fluorescence microscopy. Lids were designed with a gap allowing gas exchange during tissue culture incubation. Cell growth for RPE1 hTERT immortalized cells was seen as even and present right to the silicone glue/plastic interface (Supplemental Figure 1).

During longer-term incubation, beyond $72 \mathrm{hrs}$, we noted a tendency of early $22 \times 50 \mathrm{~mm}$ chamber designs on $22 \times 50 \mathrm{~mm}$ coverslips to warp $0.5 \mathrm{~mm}$ due to the absorption of humidity by the plastic. This warping was caused by a $1 \%$ expansion of the length of the plastic, but not the glass. The design solution for longer-term experiments (days to weeks) was to use a $22 \times 22 \mathrm{~mm}$ chamber design with a 6-chamber holder (Fig.4). This additionally allowed for greater modular flexibility to match the needs of the experimental setup in regards to the number of wells required. Another alternative was to have two linked 22x22mm chambers glued to two $22 \times 22 \mathrm{~mm}$ coverslips that fit within the $22 \times 50 \mathrm{~mm}$ holder format. For longer-term live-cell observations, we designed another holder, where single chambers fit within a Tokai HIT incubated stage (Tokai, Japan). The holder maintains the chamber at the correct height while still allowing a pressure seal to prevent $\mathrm{CO}_{2}$ loss and heat escape (Fig.4). The holder takes advantage of a unique PLA formulation that is thermochromic between $32-45^{\circ} \mathrm{C}$. This allows the user a simple visual confirmation of temperature with a transition from grey to orange at $37^{\circ} \mathrm{C}$, with a second transition to yellow at $42^{\circ} \mathrm{C}$ for heat shock experiments (Figure 4 , panels b-d).

As an example of utility, a 22x22 single well chamber was used to culture live human RPE1 cells and subjected to a laser stripe DNA damage assay at $37^{\circ} \mathrm{C}$ (Figure 5). After 24 hours of culture and transfection, PARP1 enzyme was visualized accumulating to sites of $405 \mathrm{~nm}$ induced DNA damage 
within 25 seconds by an anti-PARP1 chromobody fused to TagRFP and then visualized for an additional 2 minutes (Supplemental Video 2).

To then take advantage of this system and fast prototyping, we designed a perfusion chamber with internal microfluidic passages that could not be created using traditional subtractive manufacturing due to the encapsulated fluid channels. Since MSLA printing has excellent resolution capabilities, we were able to design a microfluidic path in a one-piece print. This model only required inserts of metal piping to connect plastic tubing to a peristaltic pump. Contrary to traditional microscopy perfusion chambers, which typically only have a single inlet and outlet, our design allowed for the even rapid distribution of fluid across the imaging area.across a manifold of one into four across the surface of the $22 \times 22 \mathrm{~mm}$ chamber (Fig. 6a). The chambers were used during tissue culture with a removable FDM printed lid bonded with silicone (Fig. 4b). However, prior to completing a perfusion experiment, a $22 \times 22 \mathrm{~mm}$ coverslip was sealed onto the top face of the chamber using silicone vacuum grease (CS16, Silicone Solutions, OH, USA).

For sterilization, we used a combination of bathing in $70 \%$ isopropyl alcohol, bathing in sterile water, and UV irradiation. Following the bathing steps, the chambers were allowed to dry, then sealed in clear plastic bags. The chambers were then UV sterilized in either a $365 \mathrm{~nm}$ chamber at $30 \mathrm{~mW} / \mathrm{cm}^{2}$ (ELC-500, Electro-Lite) for 5 minutes per side, or in a bespoke 3D-printing curing/sterilization chamber. The curing/sterilization chamber was lined with aluminum foil tape and used an inexpensive ( US\$40) 30W 385nm LED array "black light" flood lamp $\left(60 \mathrm{~mW} / \mathrm{cm}^{2}\right)$ (WOWTOU, China) (Fig. 3) for at least 30 minutes per side, flipping once to avoid shadows. To ensure sterilization, previously prepared chambers from storage were irradiated with UV once more, and individual wells were washed with PBS and media before plating. This protocol ensured complete sterilization without any need for heat. .

The modular system resulted in significant cost savings over commercially-sourced imaging chambers. $22 \times 22 \mathrm{~mm}$ single chambers cost 20 cents total: 2 cents in plastic and 18 cents in glass. Double chambers cost 44 cents, with the coverslips contributing to the bulk of the cost. Overall, our Mod3D solution costs $1 / 25$ th of what their commercial solution counterparts (Table 1).

\section{Materials and Methods}

3D Printing

Models were designed by Computer Aided Design (CAD) in Fusion360 software (AutoCAD, USA) or the free web-based TinkerCAD software (https://www.tinkercad.com/). 3D models were exported as STereoLithography (.stl) files and used to generate G-code in either Cura 4.11 (Ultimaker) for FDM printing or in Chitubox freeware (https://www.chitubox.com/) for resin printing. For FDM, models were printed at $20 \%$ grid infill with a layer height of $0.16 \mathrm{~mm}$ on either a Creality Ender 3 or a CR10 printer (Creality, Shenzhen, China). Polylactic acid (PLA) or Polyethylene Terephthalate Glycol (PETG) $1.75 \mathrm{~mm}$ filament was sourced from 3D Printing Canada (https://3dprintingcanada.com/). For chamber holder tops and bottoms, printing was completed with a $>6 \mathrm{~mm}$ brim on the bottom to ensure the print remained flat. To minimize warping, the print was not removed from the heated print bed until both had cooled to room temperature. Within the print, four neodymium $5 \times 1 \mathrm{~mm}$ magnets were glued into place on each top and bottom half of the chamber holder with polyurethane or cyanoacrylate glue.

For MSLA, an Anycubic Photon printer (Anycubic, Shenzhen, China) was used with eSun PLA biocompatible resin LC1001 (Shenzhen eSUN Industrial Co., China) using the standard settings for that printer located in the Chitubox profile. Each print used black resin and contained four $22 \times 50 \mathrm{~mm}$ chambers or eight $22 \times 22 \mathrm{~mm}$ chambers. Chambers were supported on the top face using $50 \%$ support density on a raft. Clear resin was only used for prototyping to confirm microfluidic flow. 
After printing, 3D prints were released from the platform and washed for 15 minutes in fresh 99\% isopropyl alcohol (IPA) in a Anycubic Wash \& Cure Plus Machine (Anycubic, Shenzhen, China). An IPA wash in a fresh solution was important to remove any toxic monomers in the uncured resin. Chambers were then removed from the print supports prior to $405 \mathrm{~nm}$ curing in the same machine, which occurred for 30 minutes on the built-in rotating turntable. Alternatively, we used the $30 \mathrm{~W} 385 \mathrm{~nm}$ flood lamp $\left(60 \mathrm{~mW} / \mathrm{cm}^{2}\right.$ ) (WOWTOU, China) placed face down on a 3D-printed box for 30 minutes, flipping once to avoid shadows.

Thermochromic PLA filament (TopZel Tritemp Lava) was sourced from TopZeal, China.

\section{Chamber assembly}

A $30 \mathrm{~mm}$ diameter, $15 \mathrm{~cm}$ wide craft roller was used to spread silicone RTV glue (SS-433T, Silicone Solutions, $\mathrm{OH}$, USA) onto a sheet of phenolic resin. Once the glue was spread evenly, the roller was used to transfer it to the bottom surface of the inverted chamber. A $22 \times 22 \mathrm{~mm} \# 1.5$ glass coverslip (VWR, USA) was then pressed onto the glue face with a 3D printed tamper block (Supplemental Video 1). The glue was allowed to fully cure for $16 \mathrm{hrs}$ in the humid environment of a tissue culture incubator, which accelerated the curing time for RTV silicone. Curing the chamber fully in high humidity was essential for preventing any potential toxicity from the curing agent. A similar protocol was used for the chamber lids. Both chambers and lids were bathed in $70 \%$ IPA for 10 minutes, followed by 10 minutes in sterile water. They were then placed in small clear polypropylene bags and UV sterilized prior to storage and use. UV sterilization was completed using either a $30 \mathrm{~mW} / \mathrm{Cm}^{2} 365 \mathrm{~nm}$ ELC-500 UV (ELC-500, Electro-Lite, USA) chamber on a rotating platform for 5 minutes per side, or the flood lamp curing chamber previously described for 30 minutes per side (Fig. 3).

DNA damage laser stripe assays

RPE1 human hTERT immortalized cells were used. Culturing conditions, 405nm laser irradiation, and microscopy equipment were as described elsewhere [4]. Poly ADP-ribose Polymerase, PARP1, enzyme was visualized with an anti-PARP1 chromobody, which comprises the anti-PARP1 $\mathrm{VHH}$ derived from alpaca heavy chain antibody genetically fused to TagRFP (Chromotech, Gmbh) to visualize endogenous PARP1.

\section{Discussion}

Early experiments in prototyping these modular designs used low-cost commercial resins, which resulted in cellular toxicity. Presumably, this was due to unpolymerized monomers that did not wash out during the isopropanol washes and subsequently solubilized in media. Thus, wash steps using fresh isopropyl alcohol were essential for this protocol. Within this industry, there are over 40 different resin formulas available. However, the exact formulations are elusive and typically guarded as an industry secret. Most resins are liquid in a methyl ethyl ketone (MEK) base, contributing to a significant odor, with MEK indicated as an irritant. Therefore all printing and handling of liquid resin were done within a chemical fume hood using gloves and goggles for handling. MEK itself is toxic and must be washed away using isopropanol. In combination with the post-printing UV curing step , isopropanol washes coincidently resulted in sterile prints.

UV resins are typically polymers of unsaturated polyester, which is an initiator and a photosensitizer [5]. The initiator is triggered by energy absorbed by the photosensitizer and is used to catalyze the polymerization. Typical polymers sold to hobby consumers are in the methacrylate family 
and are known to have toxic properties $[6,7]$. However, the industry has recently evolved to produce more biocompatible polymers called "bio inks" [8][9]. These include polycaprolactone, polylactic acid (PLA) and polyglycolic acid (PGA) and are FDA-approved for biological use [5][10][11]. Of these, PLA resin (e-resin PLA, eSun, China) was affordable and available in our region. One unanticipated advantage to polylactic acid plastic was the lack of surface charge seen in polystyrene products. Surface charges can lead to liquid transfer problems and have a high meniscus effect in small wells. We did not experiment above 16-wells per chamber (or 96-wells per holder), but the limitation of the printer resolution should not be a factor for higher well densities. MSLA resin prints have a higher resistance to temperature than FDM PLA prints, and display higher flexibility with no deformation up to $100^{\circ} \mathrm{C}$. In early $22 \times 50 \mathrm{~mm}$ designs, we did note the expansion of chamber dimensions by up to $1 \%$. The expansion of the chamber was due to the absorbance of moisture by the plastic within the tissue culture incubator and resulted in a $0.5 \mathrm{~mm}$ warp on the chamber glass. This is because over three days, the plastic that was bonded to the glass expanded, while the glass coverslip did not. This warping was resolved using either a linked $22 \times 22 \mathrm{~mm}$ twin chamber design or by using $22 \times 22 \mathrm{~mm}$ chambers in a 6-chamber holder.

The modular nature of the chambers allows for efficient use of the wells based on experimental need, and therefore there is less waste from unused wells in commercially available multiwell plates. The chamber carriers, the chambers and the lid frames were made from biodegradable PLA resin or filament [12]. The cost savings were dramatic, with a chamber costing under 30 cents, in contrast to some of the commercial examples charging over US\$10. One practical aspect is the flexibility to integrate new designs. Prototypes can be generated at minimal cost in just a few hours, without the practical limitations of a local machine shop. MSLA printing time, unlike FDM, does not scale with replicates; printing one, four or eight chambers is completed at the same time. This is because the time-limiting step in MSLA is dictated by the height of the objects in the print area, not the number of objects, as all object layers are simultaneously exposed to UV mask. With FDM, print time is dictated by height, in Z, and tool movement of the extruder head, in XY. Newer MSLA printers use 4X or 8X larger screens (based on consumer computer tablet $4 \mathrm{~K}$ or $8 \mathrm{~K}$ LCDs), which could generate 16-32 $22 \times 50 \mathrm{~mm}$ or $32-6422 \times 22 \mathrm{~mm}$ chambers in the same 90 minute time-frame. Similarly, inexpensive consumer FDM printers on coreXY design are now available at printing speeds of up to $250 \mathrm{~mm} / \mathrm{sec}$, or five times the speed of typical printers of a few years ago.

The advantages of additive local manufacturing all come into play with these designs: low cost, minimized inventory maintenance, no lag times between ordering, decreased worrying about availability and shipping costs. The assembled modular nature also means the chamber holder and lids can be reused after sterilization. The craft skills and hands-on time per step required are minimal, and a naive user can generate up to 40 chambers a day (Supplemental Video 1).

The cost of 3D printing materials and equipment is now much lower because of the expanding home consumer market. Additionally, we used a black light 30W 385nm LED flood lamp array as an inexpensive post-print processing equipment for curing and sterilization. For total equipment investment, cost recovery is realized in under 100 chambers. The 3D printing designs are freely and openly distributed on a curated website (https://3dprint.nih.gov/) under Open Licence. With more submissions from users for unique applications in the future, this repository should grow in designs since the cycle from concept to prototype and the ability to generate experiment-specific designs is now reduced to a negligible time and cost. 


\section{References}

1. Jones R, Haufe P, Sells E, Iravani P, Olliver V, Palmer C, et al. RepRap - the replicating rapid prototyper. Robotica. 2011;29: 177-191.

2. Singh R, Gehlot A. Intelligent circuits and systems: Proceedings of the 3rd international conference on intelligent circuits and systems (ICICS 2020) June 26-27, 2020 Punjab, India. London: CRC Press; 2021.

3. Howell JL, Truant R. Live-cell nucleocytoplasmic protein shuttle assay utilizing laser confocal microscopy and FRAP. Biotechniques. 2002;32: 80-2, 84, 86-7.

4. Maiuri T, Mocle AJ, Hung CL, Xia J, van Roon-Mom WMC, Truant R. Huntingtin is a scaffolding protein in the ATM oxidative DNA damage response complex. Hum Mol Genet. 2017;26: 395-406.

5. Hartings MR, Ahmed Z. Chemistry from 3D printed objects. Nature Reviews Chemistry. 2019;3: 305-314.

6. Hoffmann A, Leonards H, Tobies N, Pongratz L, Kreuels K, Kreimendahl F, et al. New stereolithographic resin providing functional surfaces for biocompatible three-dimensional printing. J Tissue Eng. 2017;8: 2041731417744485.

7. Mautner A, Qin X, Kapeller B, Russmueller G, Koch T, Stampfl J, et al. Efficient curing of vinyl carbonates by thiol-ene polymerization. Macromol Rapid Commun. 2012;33: 2046-2052.

8. Prakash C, Singh S, Singh R, Ramakrishna S, Pabla BS, Puri S, et al. Biomanufacturing. Springer International Publishing; 2019.

9. Narayanan LK, Huebner P, Fisher MB, Spang JT, Starly B, Shirwaiker RA. 3D-Bioprinting of Polylactic Acid (PLA) Nanofiber-Alginate Hydrogel Bioink Containing Human Adipose-Derived Stem Cells. ACS Biomater Sci Eng. 2016;2: 1732-1742.

10. Giordano RA, Wu BM, Borland SW, Cima LG, Sachs EM, Cima MJ. Mechanical properties of dense polylactic acid structures fabricated by three dimensional printing. J Biomater Sci Polym Ed. 1996;8: 63-75.

11. Mulla MZ, Rahman MRT, Marcos B, Tiwari B, Pathania S. Poly Lactic Acid (PLA) Nanocomposites: Effect of Inorganic Nanoparticles Reinforcement on Its Performance and Food Packaging Applications. Molecules. 2021;26: 1967.

12. Zaaba NF, Jaafar M. A review on degradation mechanisms of polylactic acid: Hydrolytic, photodegradative, microbial, and enzymatic degradation. Polym Eng Sci. 2020. doi:10.1002/pen.25511 


\section{Figure Legends}

Figure 1. Mod3D live-cell microscopy system. (a) Examples of $22 \times 50 \mathrm{~mm} 3$-chamber holders in the universal 96-well plate format, with MSLA printed chambers, FDM printed holder, inserted magnets and reusable PLA/polystyrene lid. (b) Examples of the 6-chamber holders with different chamber designs. (c-e), Modularity and assembly of the system, where the holders and the lids are reusable.

Figure 2. Examples of varieties of chamber designs in Mod3D. (a,b) Examples of embossed alphanumeric labels on 4-well $(750 \mu \mathrm{l}$ per well) or 16 -well $(145 \mu \mathrm{l}$ per well) chambers. (c) Round single well design $(2.8 \mathrm{ml})$. (d) Example of glass bonding using RTV silicone at the bottom of the chambers. (e) Example of 8-well chambers (260 $\mu \mathrm{l}$ per well). (f) Bridged 2-well chambers in 22x50 mm format, shown bonded to 22x22 mm glass coverslips in (g). (h) Bridged 2-well chambers bonded to a 22x50 $\mathrm{mm}$ glass coverslip, with reusable plastic lid.

Figure 3. Chamber UV sterilization. (a) 3D printed curing/sterilization chamber lined with aluminum foil tape with a 30W $385 \mathrm{~nm}$ LED flood lamp placed on top. (b) Alternate method of chamber sterilization in a UV curing chamber with rotating platform (Electrolite ELC-500). In both methods the chambers are placed in clear polypropylene bags.

Figure 4. Thermochromic Chamber holder for live-cell incubator stage. (a) Left to right: the lid, chamber, and holder. (b) Assembly of the chamber and holder in the stage at $25^{\circ} \mathrm{C}$ with grey color. (c) Placement of the chamber and holder within the incubated temperature and gas control chamber at $37^{\circ} \mathrm{C}$ with color change to orange. (d) As in panel c, but temperature increased to $42^{\circ} \mathrm{C}$ (yellow).

Figure 5. Sample Live Cell Confocal microscopy data. RPE1 cell expressing PARP1 chromobody as red fluorescent protein fusion. (a) After $24 \mathrm{hrs}$ growth, immediately after 405nm laser irradiation in the region defined by yellow box. (b) 12 seconds later. Panel c, 25 seconds later, showing PARP1 chromobody recruitment to the site of induced DNA damage. Scale bar is 10um. Timestamp is seconds and milliseconds. $60 \mathrm{X}$ oil objective.

Figure 6. Bespoke Mod3D perfusion chamber. (a) Computer Aided Design (CAD) drawing of microfluidic paths and the 1:4 manifolds. (b) Chamber, culture lid and perfusion lid clamp. (c) A 22x22 $\mathrm{mm}$ coverslip is placed on top after cell culture sealed with silicone grease and clamped into place with the PETG clamp. Inlet/outlet aluminum tubing is bonded in place with RTV silicone.

Supplemental Figure 1. Growth of human RPE1 hTERt-immortalized cells in Mod3D chamber by brightfield inverted microscopy. (a) even growth across glass surface showing typical density and contact-inhibition of RPE1 line. (b) RPE1 growth near the plastic chamber border. Scale bars are 1000uM.

Supplemental Video 1. Gluing and assembly of Mod3D chambers to glass slides and incubation for curing.

Supplemental Video 2. Extended Live cell DNA damage laser stripe assay data from figure 6, over 134 seconds, with timestamp. 
bioRxiv preprint doi: https://doi.org/10.1101/2021.10.18.462400; this version posted October 19, 2021. The copyright holder for this preprint (which was not certified by peer review) is the author/funder. All rights reserved. No reuse allowed without permission.

Figure 1

a

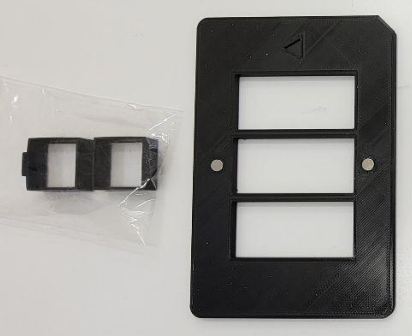

Chamber
Holder bottom $22 \times 50$

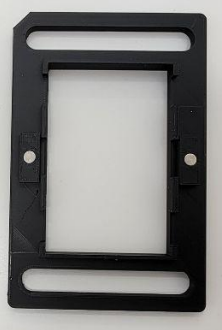

Holder Top $22 \times 50$
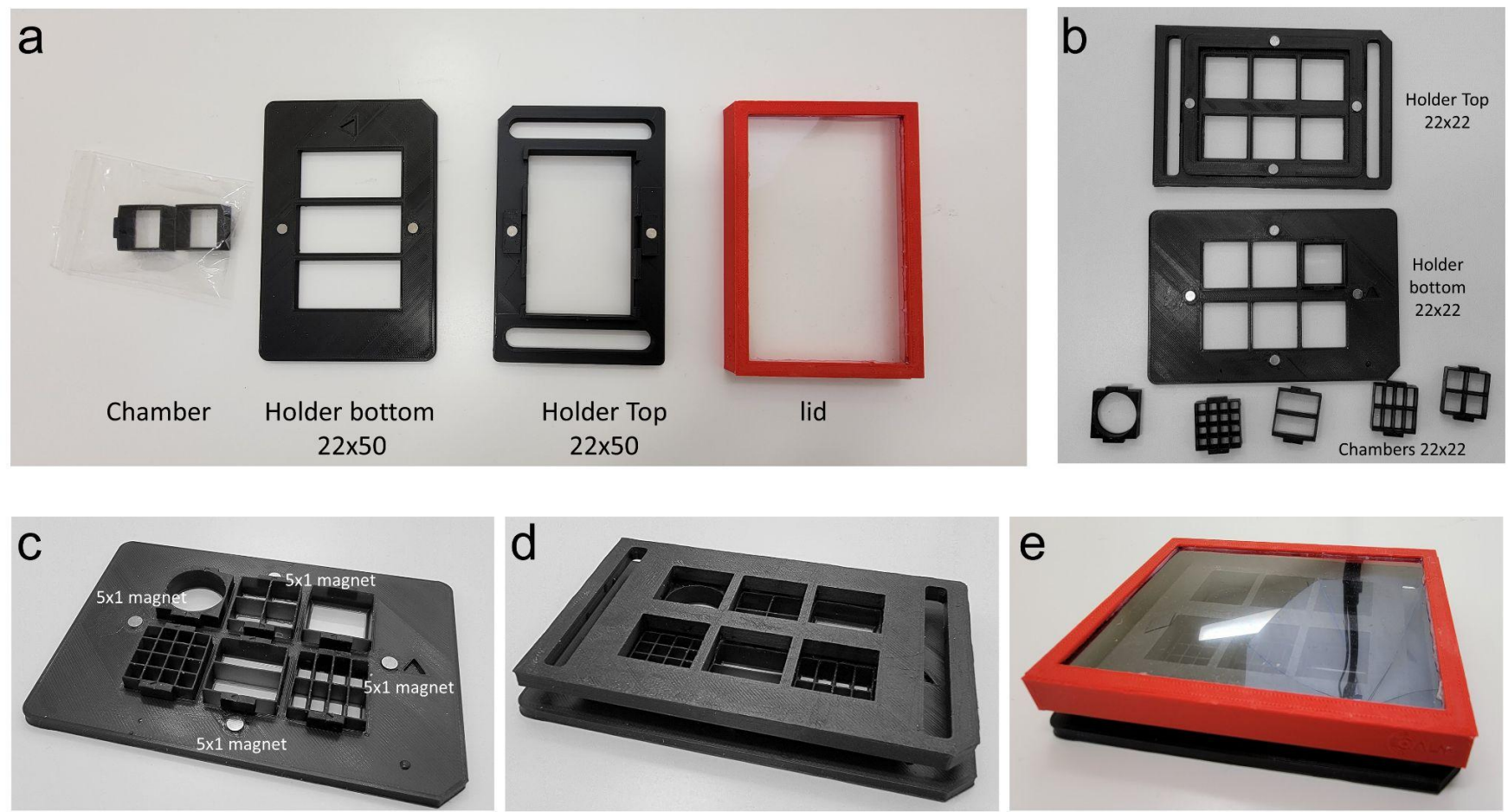
bioRxiv preprint doi: https://doi.org/10.1101/2021.10.18.462400; this version posted October 19, 2021. The copyright holder for this preprint (which was not certified by peer review) is the author/funder. All rights reserved. No reuse allowed without permission.

Figure 2
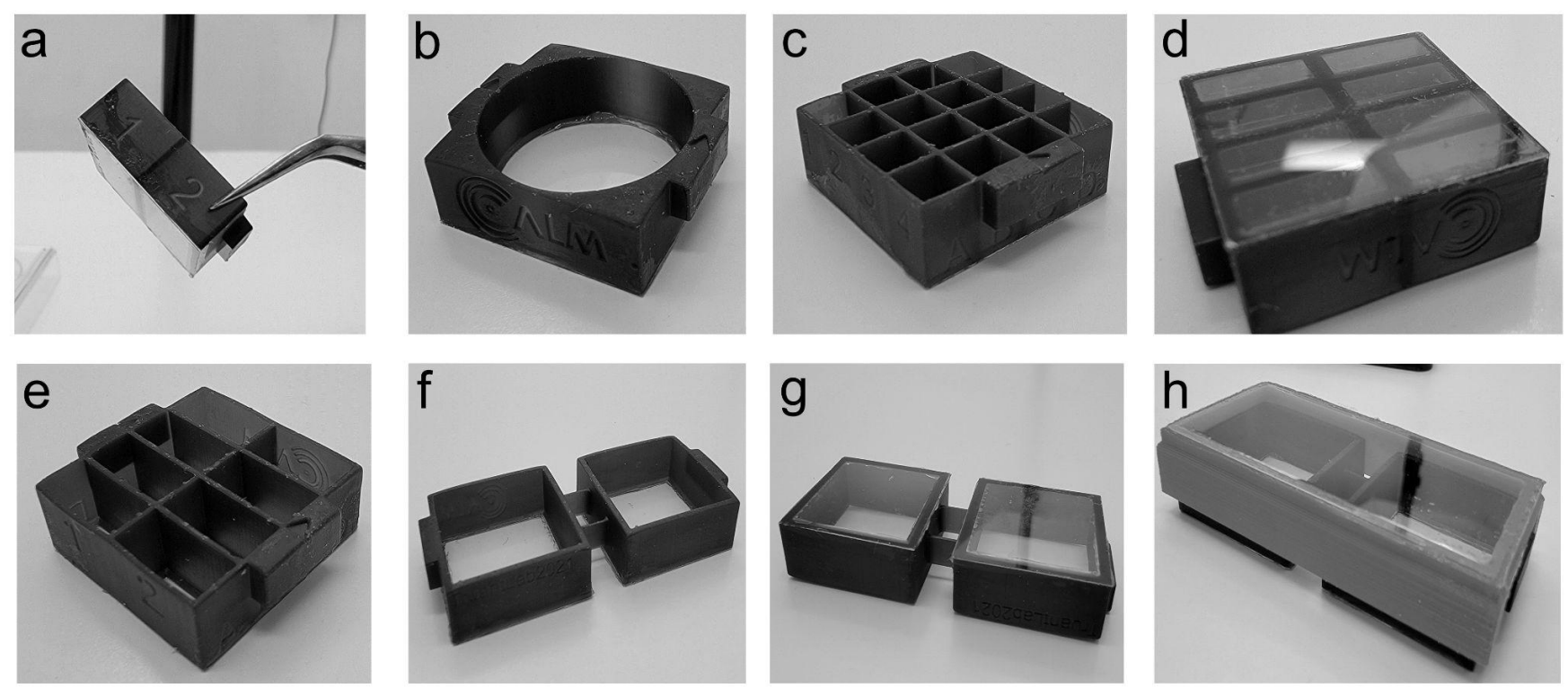
bioRxiv preprint doi: https://doi.org/10.1101/2021.10.18.462400; this version posted October 19, 2021. The copyright holder for this preprint (which was not certified by peer review) is the author/funder. All rights reserved. No reuse allowed without permission.

Figure 3
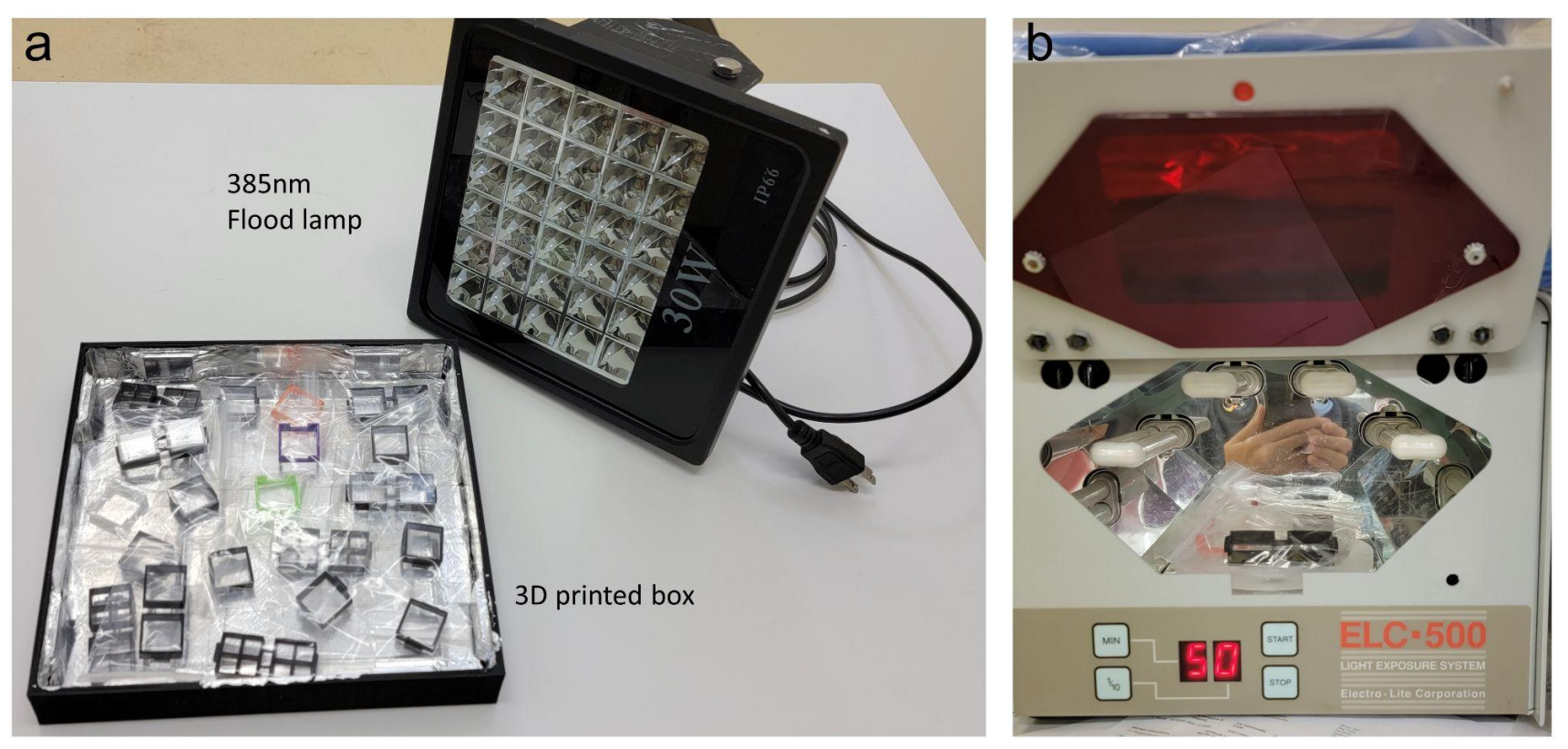
bioRxiv preprint doi: https://doi.org/10.1101/2021.10.18.462400; this version posted October 19, 2021. The copyright holder for this preprint (which was not certified by peer review) is the author/funder. All rights reserved. No reuse allowed without permission.

Figure 4
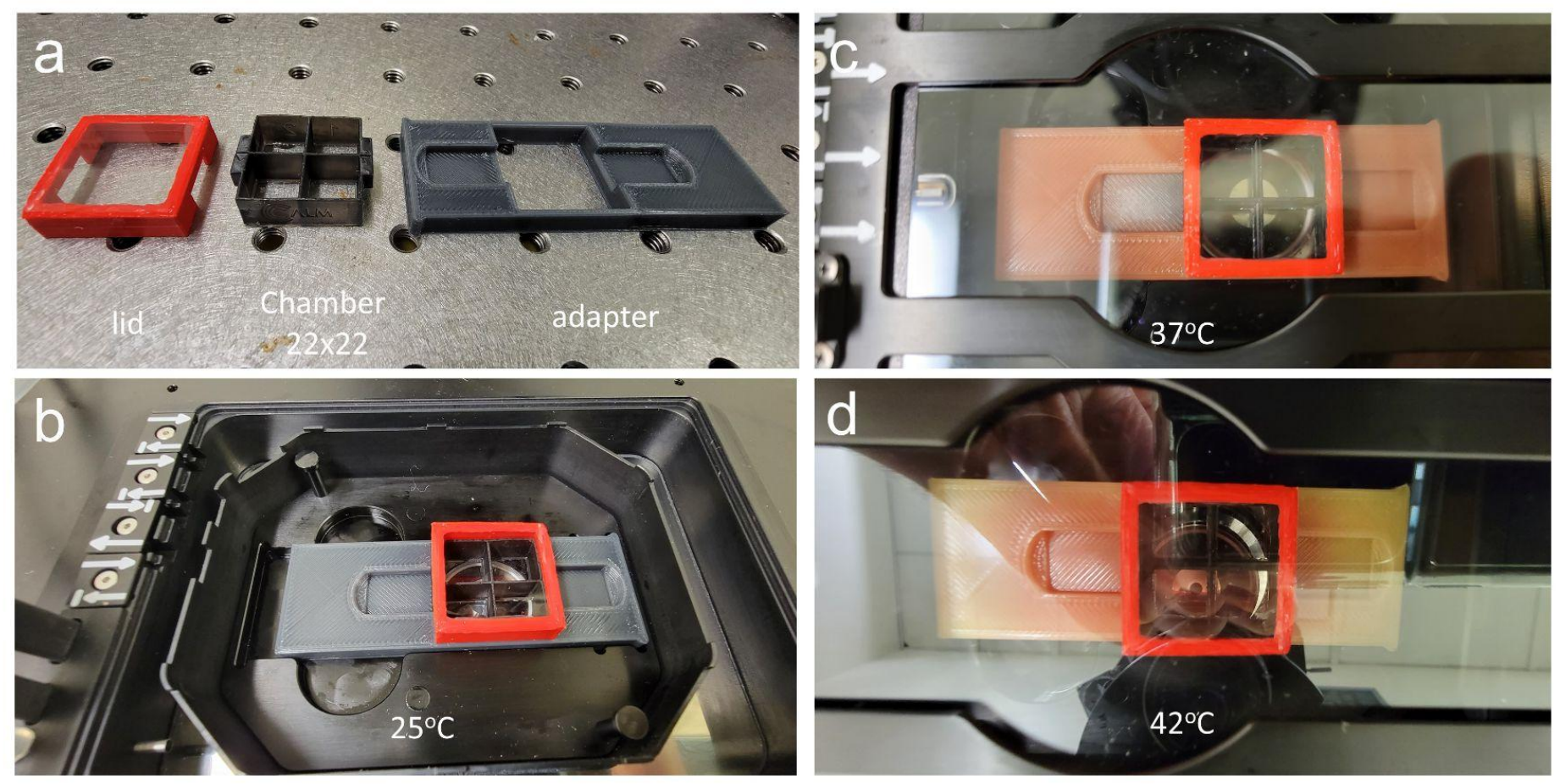
bioRxiv preprint doi: https://doi.org/10.1101/2021.10.18.462400; this version posted October 19, 2021. The copyright holder for this preprint (which was not certified by peer review) is the author/funder. All rights reserved. No reuse allowed without permission.

\section{Figure 5}
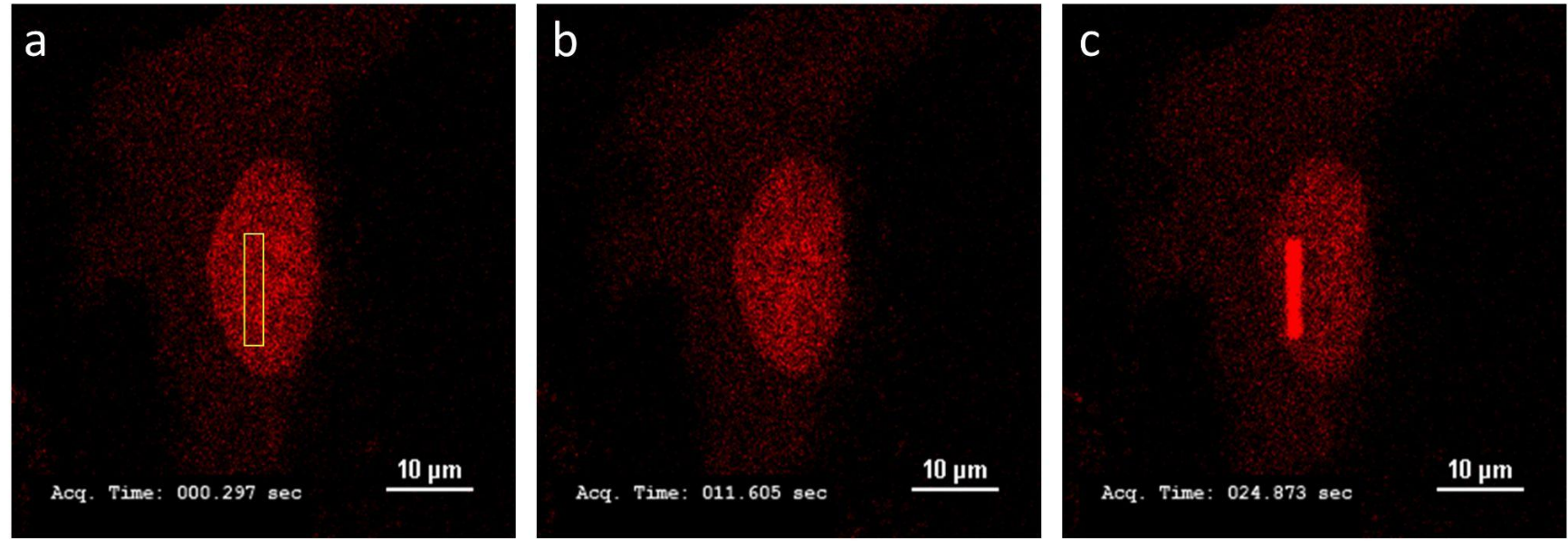
bioRxiv preprint doi: https://doi.org/10.1101/2021.10.18.462400; this version posted October 19, 2021. The copyright holder for this preprint (which was not certified by peer review) is the author/funder. All rights reserved. No reuse allowed without permission.

Figure 6
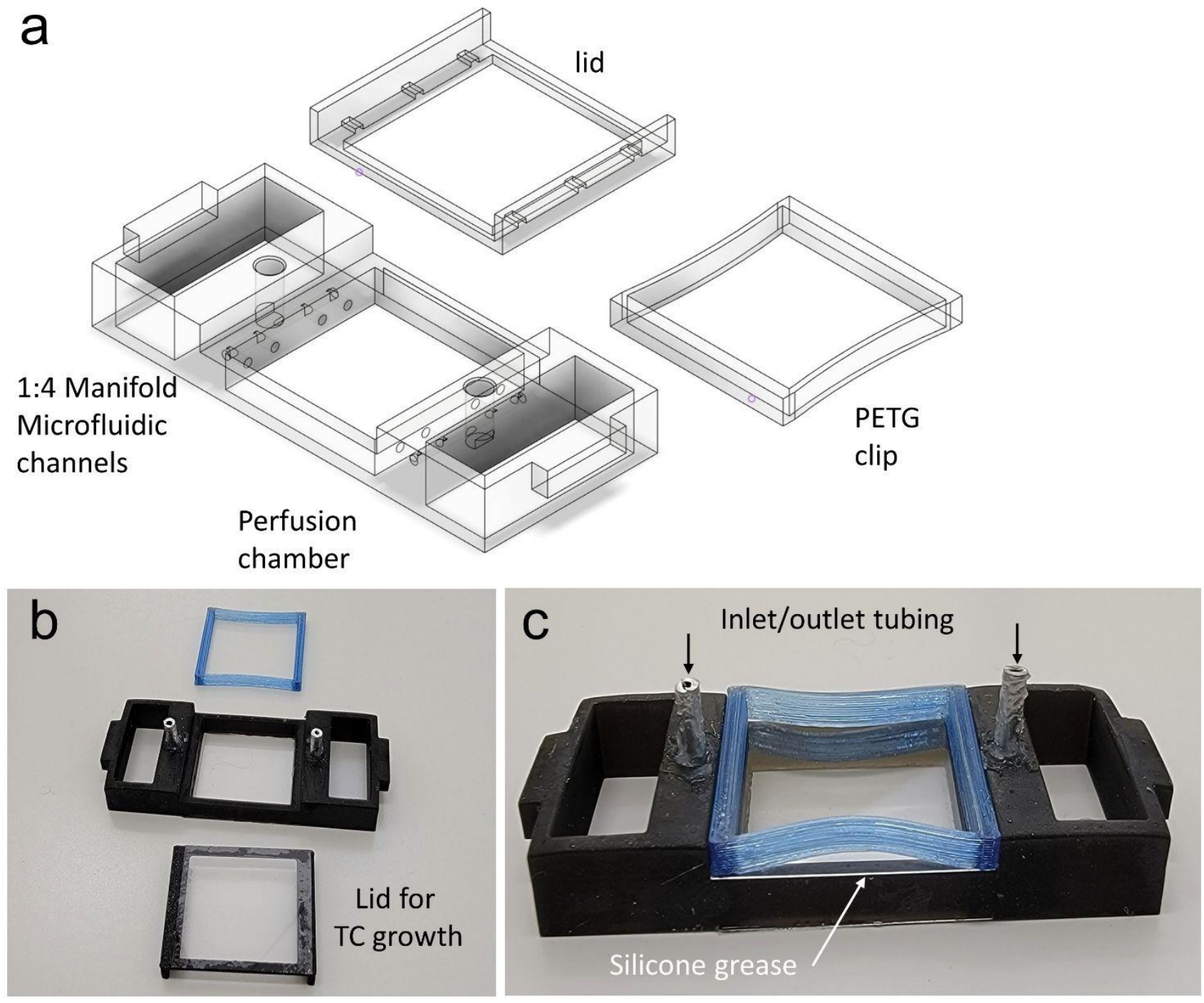
Table 1. Cost comparisons of commercially available imaging chambers and the 3D printed microscopy chambers

\begin{tabular}{|c|c|c|c|c|}
\hline Product Name & Retailer & $\begin{array}{l}\text { Catalog } \\
\text { Number }\end{array}$ & Description & $\begin{array}{l}\text { Approximate } \\
\text { Cost Per } \\
\text { Chamber } \\
\text { (\$USD) }\end{array}$ \\
\hline $\begin{array}{l}\text { Thermo Scientific }{ }^{\mathrm{TM}} \\
\text { Nunc }^{\mathrm{TM}} \text { Lab-Tek }^{\mathrm{TM}} \\
\text { Chamber Slide }^{\mathrm{TM}}\end{array}$ & $\begin{array}{l}\text { ThermoFisher } \\
\text { Scientific }\end{array}$ & 177402PK & $\begin{array}{l}25 \times 75 \mathrm{~mm} \text { 8-well } \\
\text { polystyrene chamber } \\
\text { on soda lime glass } \\
\text { microscope slide }\end{array}$ & 14 \\
\hline $\begin{array}{l}\mu \text {-Slide 8-Well } \\
\text { Glass Bottom }\end{array}$ & Ibidi® & 80827 & $\begin{array}{l}25.5 \times 75.5 \mathrm{~mm} \text { 8-well } \\
\text { plastic chamber on } \\
\text { Schott glass slide }\end{array}$ & 12 \\
\hline $\begin{array}{l}\text { Eppendorf Cell } \\
\text { Imaging Slide }\end{array}$ & Eppendorf & 0030742079 & $\begin{array}{l}26 x 76 \mathrm{~mm} \text { 8-well } \\
\text { plastic chamber on } \\
\text { soda lime glass } \\
\text { microscope slide }\end{array}$ & 13 \\
\hline $\begin{array}{l}\text { 8-Well Culture } \\
\text { Slides }\end{array}$ & $\begin{array}{l}\text { MatTek Life } \\
\text { Sciences }\end{array}$ & CCS-8 & $\begin{array}{l}\text { Polystyrene chamber } \\
\text { on glass microscope } \\
\text { slide }\end{array}$ & 9.3 \\
\hline $\begin{array}{l}\text { Mod3D live-cell } \\
\text { Microscopy } \\
\text { Chamber }\end{array}$ & $\mathrm{N} / \mathrm{A}$ & $\mathrm{N} / \mathrm{A}$ & $\begin{array}{l}22 \times 22 \mathrm{~mm} / 22 \times 50 \mathrm{~mm} \\
\text { polylactic acid } \\
\text { chamber on glass } \\
\text { microscope slide }\end{array}$ & $\begin{array}{l}0.20(22 \times 22 \\
\mathrm{mm}) \\
0.55(22 \times 50 \\
\mathrm{mm})\end{array}$ \\
\hline
\end{tabular}

